\title{
REMEDIATION OF SOLID MATRIX CONTAINING ANTHRACENE AND PHENANTHRENE BY PERMANGANATE OXIDANT
}

\author{
SILVA C.K.O. ${ }^{1,2}$, \\ AGUIAR L.G. ${ }^{2}$ \\ CIRIACO M.F. ${ }^{3}$ \\ VIANNA M.M.G.R. ${ }^{2}$ \\ NASCIMENTO C.A.O. ${ }^{2}$ \\ CHIAVONE-FILHO O. ${ }^{1}$ \\ PEREIRA C.G. ${ }^{1}$ \\ FOLETTO E.L.,
}

\author{
${ }^{1}$ Department of Chemical Engineering \\ Federal University of Rio Grande do Norte \\ 59072-970, Natal, Brazil \\ ${ }^{2}$ Department of Chemical Engineering \\ University of São Paulo, 05508-900, São Paulo, Brazil \\ ${ }^{3}$ Institute of Chemistry \\ University of São Paulo, 05508-000, São Paulo, Brazil \\ ${ }^{4}$ Department of Chemical Engineering
}

Federal University of Santa Maria, 97105-900, Santa Maria, Brazil

Received: $13 / 12 / 2013$

Accepted: 04/04/2014

Available online: 08/04/2014 *to whom all correspondence should be addressed: e-mail: efoletto@gmail.com

\section{ABSTRACT}

This paper reports on a systematic study of the degradation of anthracene and phenanthrene in sandy soil treated with an aqueous solution of $\mathrm{KMnO}_{4}$. A kinetic model was developed based on the soil/solution ratio to predict the degradation rates of anthracene and phenanthrene. The degradation profiles achieved with the best dosage were also determined. The proposed model provided a reasonable prediction of acceptable residual contaminant concentrations. The oxidation efficiency was found to be higher than the value provided by the treatment in which the reduction of $\mathrm{KMnO}_{4}$ to $\mathrm{MnO}_{2}$ is considered to be the only reduction mechanism.

Keywords: remediation, oxidation, kinetic, anthracene, phenanthrene, soil

\section{Introduction}

Polycyclic Aromatic Hydrocarbons (PAH) is a class of environmental pollutants that accumulate due to a variety of anthropogenic activities. This type of contaminant is released during the incomplete combustion of coal, petroleum products and wood (Ferrarese et al., 2008). Soil contamination by PAH is of great concern since many of them exhibit carcinogenic and mutagenic effects and are environmentally persistent. Natural degradation mechanisms are often unable to degrade PAH molecules due to their recalcitrant nature, thus requiring a more aggressive chemical approach for successful remediation (Brown et al., 2003). An alternative is in situ chemical oxidation (ISCO) (YukselenAksoy et al., 2010; Akyol and Yolcubal, 2013; Doğan et al., 2013; Mahmoudi et al., 2013). ISCO is based on the oxidative power of chemical species, and involves the insertion of a chemical oxidant into the soil subsurface to transform groundwater or soil contaminants into less harmful chemical species (USEPA, 2006).

Various oxidants have been used in the process of in situ chemical oxidation (Nadim et al., 2006; Perraudin et al., 2007; Petri et al., 2011; Liang et al., 2012; Lo et al., 2012). The selection of an oxidant

Silva C.K.O., Aguiar L.G., Ciriaco M.F., Vianna M.M.G.R., Nascimento C.A.O., Chiavone-Filho O., Pereira C.G. and Foletto E.L. (2014), Remediation of solid matrix containing anthracene and phenanthrene by permanganate oxidant, Global NEST Journal, 16(2), 393-401. 
should be based on an evaluation of the advantages and disadvantages according to the area to be remediated. Permanganate is a powerful oxidant available in the form of potassium permanganate $\left(\mathrm{KMnO}_{4}\right)$ or sodium permanganate $\left(\mathrm{NaMnO}_{4}\right)$. Brown et al. (2003) evaluated an oxidative treatment with potassium permanganate to reduce the concentration of a mixture of six PAHs (anthracene, benzo(a)pyrene, chrysene, fluoranthene, phenanthrene, and pyrene) in contaminated soils. Results of this study demonstrated that the greatest reduction in soil concentration was observed for benzo(a)pyrene, pyrene, phenanthrene, and anthracene at $72.1,64.2,56.2$, and $53.8 \%$, respectively, in $30 \mathrm{~min}$ at a $\mathrm{KMnO}_{4}$ concentration of $160 \mathrm{mM}$. Kim and Choi (2002) proposed a mathematical model for the equilibrium to investigate the feasibility of in situ ozone venting for the remediation of unsaturated soils contaminated with phenanthrene. This study showed that the sensitivity analysis indicated that soil organic matter is the single most important factor affecting in situ ozonation for the remediation of unsaturated soil contaminated with phenanthrene. In addition, the models were found to be insensitive to the reaction mechanisms of phenathrene with either gas-phase ozone or dissolved ozone. However, the literature presents scarce information about the kinetic modeling of systems involving remediation of soil contaminated with anthracene and phenanthrene, and about their equilibrium data in soil/oxidation solution. Practical applications of kinetic modeling carried out in this study include optimization and efficient use of materials, avoiding a waste of time and oxidant. Furthermore, the modeling description can be used for design of new formulations of soil treatment, reducing the number of experiments to be performed in future studies.

In this context, the kinetic profile of the degradation of phenanthrene and anthracene in a solid matrix (sand) was evaluated. The sand was chosen as solid matrix rather than real soil to avoid competition that may occur between potential interfering materials present in the soil. These interferences include the presence of organic matter, metals and clay.

\section{Material and Methods}

\subsection{Materials}

The model soil under study was acquired from a Jacuzzi ${ }^{\circledR}$ manufacturer. This material was sand, with a controlled particle size (particle diameter of $0.5 \mathrm{~mm}$ ), composed predominantly of silica $\left(\mathrm{SiO}_{2}\right)$, with an apparent density of $1.4 \mathrm{~g} \mathrm{ml}^{-1}$ and porosity of 0.26 . The contaminants were anthracene (high purity, Aldrich) and phenanthrene ( $98 \%$ purity, Fluka Analytical). The oxidant was potassium permanganate ( $99 \%$ purity, Vetec). The oxidation was halted with sodium thiosulfate, and any remaining colloidal particles were removed with calcium chloride. Dichloromethane (99.5\% Nuclar), acetone (99.5\% Vetec) and hexane (99\% Vetec) were used as solvents.

\subsection{Methods}

The model soil was first washed and then oven-dried at $60{ }^{\circ} \mathrm{C}$ for $24 \mathrm{~h}$. Anthracene and phenanthrene were dissolved in dichloromethane (DCM) to form solutions at concentrations of 14 and $72 \mathrm{~g} \mathrm{l}^{-1}$, respectively. These solutions were then added to the soil, resulting in the following concentrations: 200 $\mathrm{mg}$ of phenanthrene and $25 \mathrm{mg}$ of anthracene per kg of dry soil.

The treatments using potassium permanganate were performed in $125 \mathrm{ml}$ Erlenmeyer flasks. Fifteen grams of contaminated sand were added to the flasks containing $30 \mathrm{~mL}$ of potassium permanganate solution. The remediation was carried out in a thermostatic bath at $25^{\circ} \mathrm{C}$. The pH was kept neutral at 7.0. In the experimental design, the dosage of permanganate in the soil and the remediation time were considered variables of the process. This experimental design also involved testing three different permanganate/soil dosages $\left(3,5,7 \mathrm{~g} \mathrm{KMnO}_{4} / \mathrm{kg}\right.$ soil) and three remediation times (24, 48 and $\left.72 \mathrm{~h}\right)$. The same methodology was used in this experiment but, $30 \mathrm{~mL}$ of an aqueous solution containing $0.07 \mathrm{~g}$ of grade $\mathrm{MnO}_{2}$ was used instead the $\mathrm{KMnO}_{4}$ solution. The reaction times were also 24, 48 and $72 \mathrm{~h}$. This extra test was performed to evaluate the influence of the $\mathrm{MnO}_{2}$ in the remediation efficiency, the $\mathrm{MnO}_{2}$ is one of the formed product during the reaction between the $\mathrm{KMnO}_{4}$ and contaminants. This parallel 
reaction was considered in the kinetic model. The runs were carried out in duplicate, for experimental error estimation. The experimental errors of the degradation results were lower than $3 \%$.

The consumption of oxidants was analyzed using the method recommended by the ASTM Standard Test Method for Determining the Permanganate Soil Oxidant Demand (PSOD-1, 2006). The demand of the oxidant was measured using the PSOD-1 Method (2006). Absorbance was measured at $525 \mathrm{~nm}$ in a Varian Cary 50 PROB UV-Vis spectrophotometer. The potassium permanganate solution was separated from the soil before stopping the reaction and transferred to a $50 \mathrm{ml}$ vial to measure the amount of oxidant consumed. One $\mathrm{mL}$ of $\mathrm{CaCl}_{2}\left(111 \mathrm{mg} \mathrm{l}^{-1}\right)$ was added to aid the removal of any remaining colloidal manganese dioxide and suspended solids. The sample was then filtered through a glass fiber filter. To avoid interferences, the cell was rinsed twice with aliquots of the filtrate before taking the readings. After separating the liquid (potassium permanganate solution) from the solid phases (soil), $1 \mathrm{~mL}$ of sodium thiosulfate was added to stop the PAH degradation reaction in the soil. Control runs were conducted in sand free of contaminants in order to check the oxidant demand.

The residual PAH in the sand was extracted by the Soxhlet method for $7 \mathrm{~h}$ with ketone and hexane, in an automatic extractor (Gerhardt Soxtherm multi-state SX PC) (EPA Method 3541). The solvents were evaporated using the RapidVap concentrator (Labconco) at $60{ }^{\circ} \mathrm{C}$. The concentrated samples were analyzed by gas chromatography-mass spectrophotometry (Shimadzu GC-MS GC-17A, DB-5MS capillary column). This method of analysis was used to identify and quantify the contaminants. The intermediates formed during the reaction were only identified by library of the GC-MS but not quantified. The quantification of phenanthrene and anthracene was done using the calibration method (five-point calibration). The chromatographic analysis was performed at an injection temperature of $250{ }^{\circ} \mathrm{C}$, using helium as carrier gas and injection of $1 \mu \mathrm{l}$ of sample (EPA Method 8270). Soxhlet extraction followed by a chromatography analysis of the sand before the contamination in laboratory was performed and it was verified that the sand samples did not present organic compounds before its use in the experiments.

\subsection{Kinetics Modeling}

According to the Interstate Technology \& Regulatory Council (ITRC, 2005), complete mineralization of phenanthrene and anthracene requires the use of a proportion of $14.7 \mathrm{~g}$ of $\mathrm{MnO}_{4}^{-}$per gram of contaminant. This proportion is equivalent to a $\mathrm{KMnO}_{4} / \mathrm{C}_{14} \mathrm{H}_{10}$ molar ratio of $22: 1$. This ratio is consistent with the stoichiometry of the anthracene and/or phenanthrene oxidation shown in reaction (1).

$$
22 \mathrm{KMnO}_{4}+\mathrm{C}_{14} \mathrm{H}_{10}+6 \mathrm{H}_{2} \mathrm{O} \rightarrow 14 \mathrm{CO}_{2}+22 \mathrm{MnO}_{2}+22 \mathrm{OH}^{-}+22 \mathrm{~K}^{+}
$$

This remediation considers the partial reduction of $\mathrm{Mn}^{7+}$ to $\mathrm{Mn}^{4+}$. However, according to Stone (1987), and Ukrainczyk and $\mathrm{McBride}$ (1992), $\mathrm{MnO}_{2}$ can oxidize organic compounds, as indicated by reaction (2).

$33 \mathrm{MnO}_{2}+\mathrm{C}_{14} \mathrm{H}_{10}+28 \mathrm{H}_{2} \mathrm{O} \rightarrow 14 \mathrm{CO}_{2}+33 \mathrm{Mn}^{2+}+66 \mathrm{OH}^{-}$

The combination of reactions (1) and (2) yields the following global reaction:

$33 \mathrm{KMnO}_{4}+\frac{5}{2} \mathrm{C}_{14} \mathrm{H}_{10}+37 \mathrm{H}_{2} \mathrm{O} \rightarrow 35 \mathrm{CO}_{2}+99 \mathrm{OH}^{-}+33 \mathrm{Mn}^{2+}+33 \mathrm{~K}^{+}$

The kinetic model is based on thermodynamic concepts. The reaction was considered to occur in an aqueous medium (ITRC, 2005), following the rate equation proposed by Forsey et al. (2010). A hypothesis was established that contaminants undergo partition between the soil and the solution. Figure 1 shows the proposed interaction scheme. 


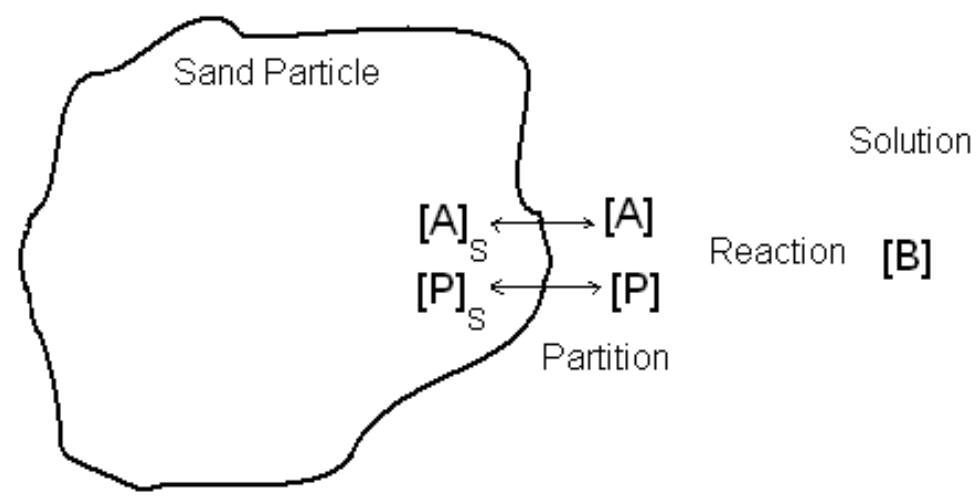

Figure 1. Interaction scheme of the contaminated soil treatment with potassium permanganate solution: [A] Anthracene concentration in the solution $\left(\mathrm{mol} \mathrm{I}^{-1}\right) ;[\mathrm{A}]_{s}$ Anthracene concentration on the soil $\left(\mathrm{mol} \mathrm{kg}^{-1}\right) ;[\mathrm{P}]$ Phenanthrene concentration in the solution $\left(\mathrm{mol} \mathrm{I}^{-1}\right) ;[\mathrm{P}]_{\mathrm{s}}$ Phenanthrene concentration on the soil $\left(\mathrm{mol} \mathrm{kg}^{-1}\right)$; [B] Potassium permanganate concentration in the solution $\left(\mathrm{mol} \mathrm{l}^{-1}\right)$.

The partition coefficients are defined in equations (4) and (5).

$\mathrm{K}_{\mathrm{PA}}=\frac{[\mathrm{A}]}{[\mathrm{A}]_{\mathrm{S}}}$

$\mathrm{K}_{\mathrm{PP}}=\frac{[\mathrm{P}]}{[\mathrm{P}]_{\mathrm{S}}}$

where $\mathrm{K}_{\mathrm{PA}}$ and $\mathrm{K}_{\mathrm{PP}}$ are the partition coefficients of anthracene and phenanthrene in the soil, respectively.

The mass transfer resistance of the components through the solution is assumed to be negligible, so most of the contaminants are presumably deposited, but no adsorbed, on the surface of the sand particles. The hypothesis of instantaneous equilibrium is valid for the present system, since the contaminant molecules are relatively small. However, this assumption can not be extended to systems containing soils with high OC content or higher molecular weight PAH. For these cases, a mass transfer study should be developed and included in the model. For that reason, Figure 1 is valid only for the present system. Based on the mechanism illustrated in Figure 1, the mass balance equation for each component in solution can be written as follows:

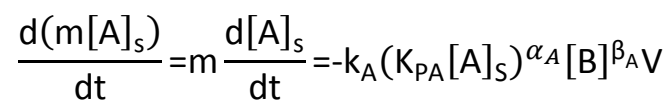

$\frac{d\left(m[P]_{S}\right)}{d t}=m \frac{d[P]_{S}}{d t}=-k_{P}\left(K_{P P}[P]_{S}\right)^{\left.\alpha_{P}[B]\right]_{P} V}$

$\left.\left.\frac{d(V[B])}{d t}=V \frac{d[B]}{d t}=-13.2 V\left(k_{A}\left(K_{P A}[B]_{S}\right)^{\alpha_{A}[B}\right]^{\beta_{A}}+k_{P}\left(K_{P P}[P]_{S}\right)^{\alpha_{P}[B]}\right]_{P}^{\beta_{P}}\right)$

where $\mathrm{k}_{\mathrm{A}}$ and $\mathrm{k}_{\mathrm{P}}$ are the kinetic constants of anthracene and phenanthrene consumption, respectively; $\alpha_{A}, \alpha_{P}, \beta_{A}$ and $\beta_{P}$ are the reaction orders; $m$ is the soil mass; and $V$ is the volume of the solution.

The value of 13.2 in equation (8) corresponds to the stoichiometric ratio of oxidant to contaminant. The value of $\mathrm{m}$ (soil mass) in equations (6) and (7) is assumed to be constant during the process, since the mass of contaminants is relatively low. Equations (6)-(8) constitute a system of ordinary differential equations and must be solved numerically, which was done using MATLAB's ODE45 algorithm. 


\section{Results and discussion}

Table 1 shows the results of PAH degradation with the three different dosages of permanganate. Note that the main differences in the degradation rates achieved with the different dosages appear in the first $24 \mathrm{~h}$ of treatment. After 3 days of treatment, the degradation rate reached a narrow range for the three oxidant dosages. The data in Table 1 also indicate that the oxidant consumption profiles are a function of the initial concentration of permanganate.

Table 1 PAHs degradation measurements

\begin{tabular}{cccccc}
\hline $\begin{array}{c}\text { Dosage } \\
\left(\mathrm{g} \mathrm{KMnO}_{4} / \mathrm{kg} \text { soil) }\right.\end{array}$ & Sample & $\begin{array}{c}\text { Remediation } \\
\text { time }(\mathrm{h})\end{array}$ & $\begin{array}{c}\text { Anthracene } \\
\text { degradation (\%) }\end{array}$ & $\begin{array}{c}\text { Phenanthrene } \\
\text { degradation (\%) }\end{array}$ & $\begin{array}{c}\text { Consumed } \\
\text { oxidant (\%) }\end{array}$ \\
\hline \multirow{2}{*}{3} & $\mathrm{~S} 1$ & 24 & 60 & 59 & 51 \\
\cline { 2 - 7 } & $\mathrm{S} 2$ & 48 & 82 & 65 & 56 \\
\cline { 2 - 6 } & $\mathrm{S} 3$ & 72 & 89 & 80 & 57 \\
\hline \multirow{2}{*}{5} & $\mathrm{~S} 4$ & 24 & 83 & 73 & 44 \\
\hline & $\mathrm{S} 5$ & 48 & 91 & 83 & 48 \\
\hline \multirow{2}{*}{7} & $\mathrm{~S} 6$ & 72 & 95 & 84 & 50 \\
\hline & $\mathrm{S} 7$ & 24 & 92 & 83 & 26 \\
\hline & $\mathrm{S} 8$ & 48 & 97 & 88 & 32 \\
\hline
\end{tabular}

The remediation results were satisfactory when compared with intervention limits, according to Dutch regulation for soils. The best results were achieved with samples S5 and S8, which presented total PAH values below $40 \mathrm{mg} \mathrm{kg}^{-1}$, as prescribed by Dutch regulation. The extraction on the sand free of contaminants showed no organics and the test involving this sand and $\mathrm{KMnO}_{4}$ solution presented no oxidant consumption. The use of a real soil containing organic matter would affect the results in terms of oxidant consumption. Part of the $\mathrm{KMnO}_{4}$ would react with organic matter, reducing the degradation efficiency. Manganese oxide is a strong oxidizing agent that can be reduced and dissolved by organic compounds, promoting efficient degradation. These oxidative processes involving manganese oxides can constitute an important abiotic degradation pathway for organic compounds in subsurface environments (Laha and Luthy, 1990).

Table 2 Reactants consumption data.

\begin{tabular}{|c|c|c|c|c|c|}
\hline Sample & $\begin{array}{c}\text { Added } \\
\text { oxidant } \\
(\mathrm{mol}) \times 10^{4}\end{array}$ & $\begin{array}{c}\text { Degraded } \\
\text { contaminant } \\
(\mathrm{mol})^{*} \times 10^{5}\end{array}$ & $\begin{array}{c}\text { Theoretical } \\
\text { oxidant } \\
\text { consumption } \\
(\mathrm{mol})^{* *} \times 10^{4}\end{array}$ & $\begin{array}{l}\text { Real oxidant } \\
\text { consumption } \\
(\mathrm{mol}) \times 10^{4}\end{array}$ & $\begin{array}{c}\text { Experimental } \\
\text { consumption relation } \\
\text { oxidant/contaminant }\end{array}$ \\
\hline S1 & \multirow{3}{*}{2.84} & 1.26 & 2.76 & 1.45 & 11.55 \\
\hline S2 & & 1.57 & 3.45 & 1.59 & 10.16 \\
\hline S3 & & 1.79 & 3.94 & 1.62 & 9.05 \\
\hline S4 & \multirow{3}{*}{4.68} & 1.63 & 3.59 & 2.06 & 12.60 \\
\hline S5 & & 1.82 & 4.00 & 2.25 & 12.35 \\
\hline S6 & & 1.87 & 4.12 & 2.34 & 12.48 \\
\hline S7 & \multirow{3}{*}{6.68} & 1.86 & 4.10 & 1.74 & 9.33 \\
\hline 58 & & 1.97 & 4.33 & 2.14 & 10.86 \\
\hline S9 & & 2.00 & 4.39 & 2.21 & 11.04 \\
\hline
\end{tabular}

*Total amount of contaminant (anthracene + phenanthrene)

**Stoichiometric values based on reaction (1) 
For this kind of treatment, Forsey (2004) and Stone (1987) reported that in a neutral pH medium, the predominant product is $\mathrm{MnO}_{2}$. This compound can oxidize products such as phenols and can enhance the oxidation process by assisting in the destruction of partially oxidized products. This process can be seen as a series of reactions that increase the overall remediation efficiency.

Table 2 compares $\mathrm{KMnO}_{4}$ consumed stoichiometrically according to reaction 1 (total mineralization) and the real values of $\mathrm{KMnO}_{4}$ consumption obtained experimentally.

Samples S2 and S3 (3 g KMnO $4 / \mathrm{kg}$ soil treated for $48 \mathrm{~h}$ and $72 \mathrm{~h}$, respectively) showed higher theoretical oxidant consumption rates than the amount of added oxidant. This suggests the occurrence of partial degradation and/or contaminant consumption by reaction with $\mathrm{MnO}_{2}$. The extra remediation test using grade $\mathrm{MnO}_{2}$ showed phenanthrene degradations of $6 \%, 13 \%$ and $17 \%$ for 24,48 and $72 \mathrm{~h}$, and anthracene degradations of $8 \%, 17 \%$ and $25 \%$ for 24,48 and $72 \mathrm{~h}$, respectively. This demonstrates a removal profile of the contaminants using grade $\mathrm{MnO}_{2}$. Furthermore, the formation of intermediary compounds such as anthraquinone, xanthone and phenanthrenequinone was detected experimentally, however the amount observed was insignificant. This experimental evidence also supports the hypothesis assumed in the modeling, i.e., total mineralization.

Figures 2 and 3 present the degradation profiles modeled at different dosages. As these figures indicate, higher degradation rates were obtained with $7 \mathrm{~g} \mathrm{KMnO}_{4} / \mathrm{kg}$ soil only in the first $24 \mathrm{~h}(92.0$ and $87.5 \%$ for anthracene and phenanthrene, respectively). On the other hand, at $3 \mathrm{~g} \mathrm{KMnO}_{4} / \mathrm{kg}$ soil, high degradation rate (89.0 and $84.5 \%$ for anthracene and phenanthrene, respectively) was only achieved after $72 \mathrm{~h}$. According to Crimi (2009), $\mathrm{MnO}_{2}$ may deposit on the subsurface of sand particles, preventing the effective distribution of oxidants and contact with contaminants. Hence, it seems reasonable to propose that $\mathrm{MnO}_{2}$ formed far away from the particle surface (in the solution) can contribute to the oxidation process through the aforementioned series reactions. On the other hand, $\mathrm{MnO}_{2}$ formed close to the particle surface may be deposited in the soil, reducing the contact of contaminants with the solution. Based on this hypothesis, the $\mathrm{MnO}_{2}$ content increases with increasing conversion (degradation), retarding the degradation process at the end of the treatment. These discrepancies are illustrated clearly in Figure 4.

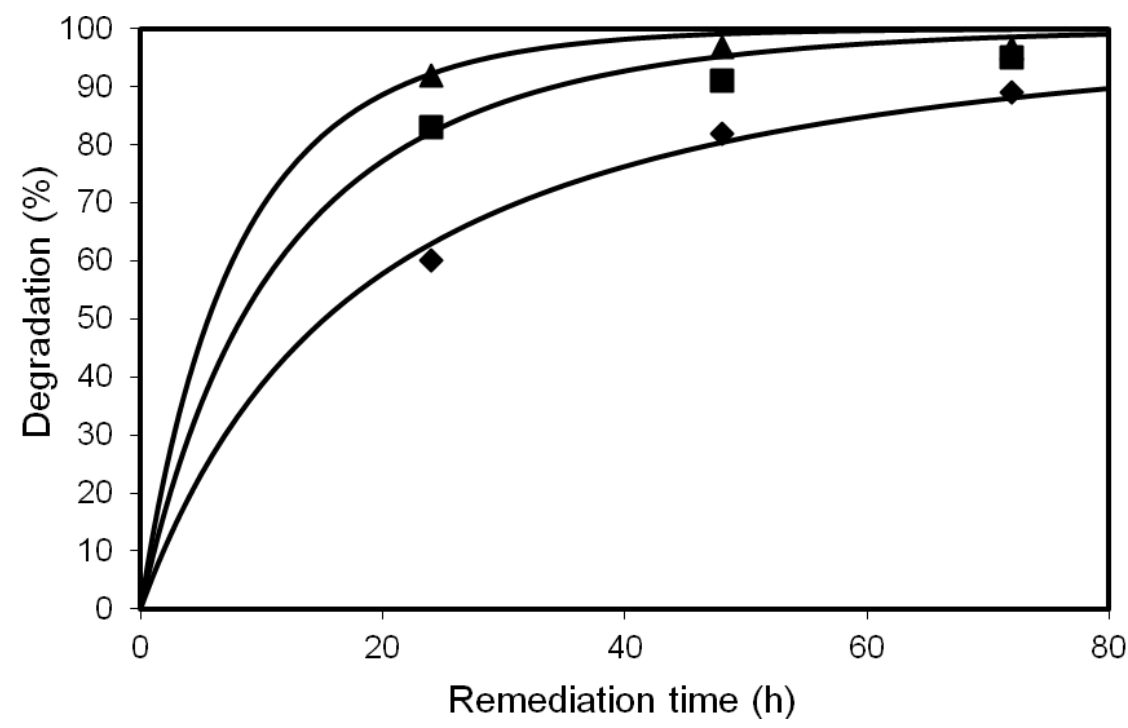

Figure 2. Degradation profiles for anthracene with permanganate potassium in different dosages: $(\downarrow) 3$, (घ) 5, and ( $\mathbf{\Delta}$ ) $7 \mathrm{~g} \mathrm{KMnO}_{4} / \mathrm{kg}$ soil; - Model (Eq. 1-3) 


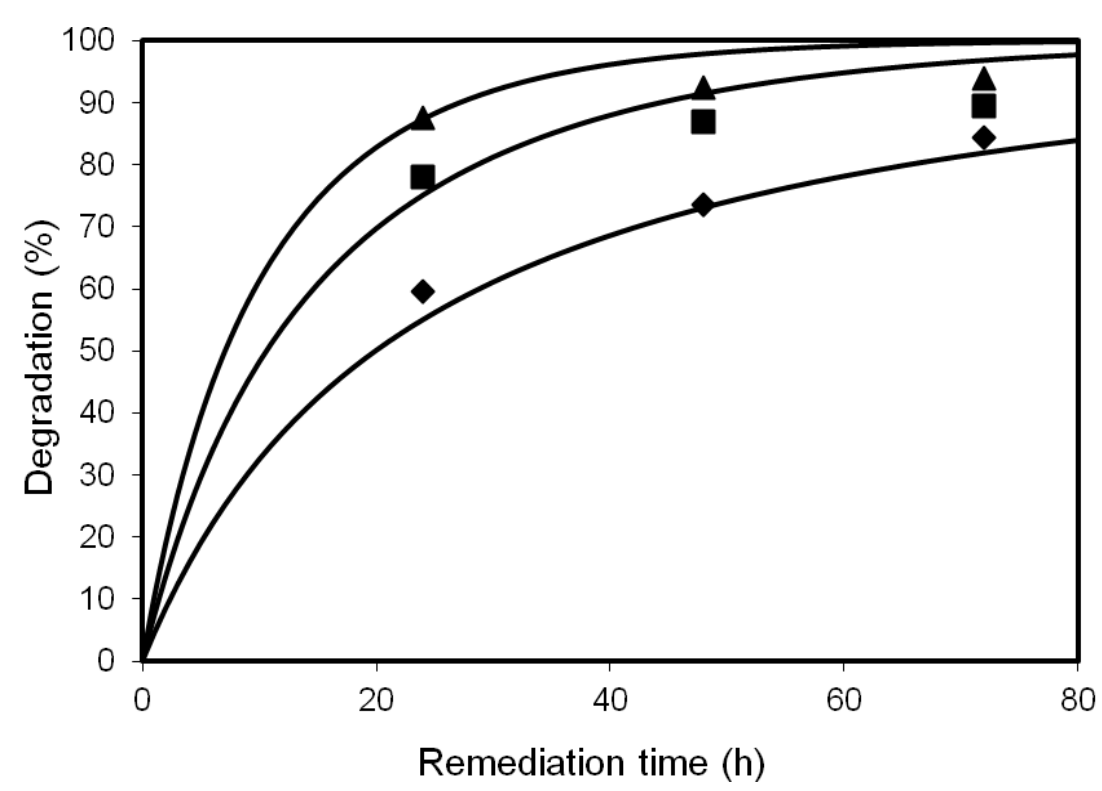

Figure 3. Degradation profiles for phenanthrene with permanganate potassium in different dosages: ( $\downarrow)$ 3, (घ) 5, and ( $\mathbf{\Delta}) 7 \mathrm{~g} \mathrm{KMnO}_{4} / \mathrm{kg}$ soil; - Model (Eq. 1-3).

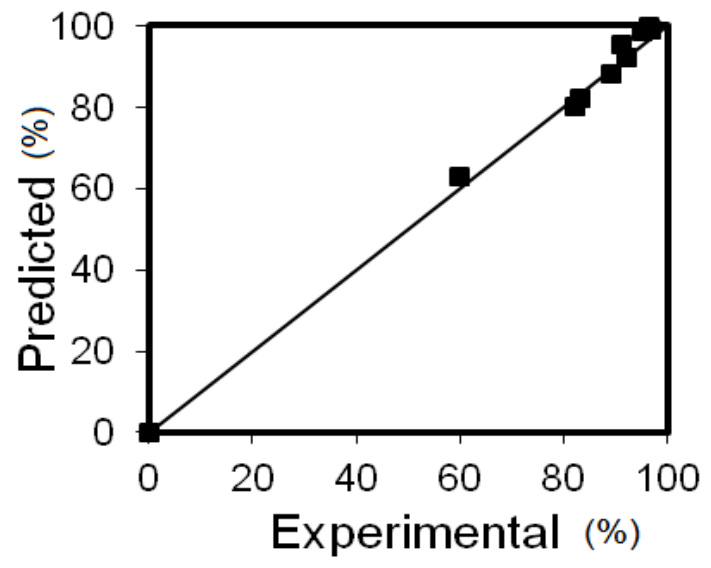

(a)

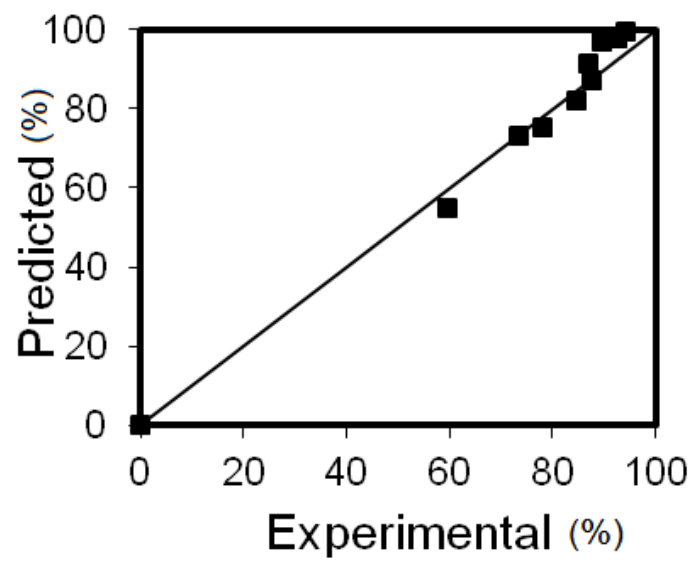

(b)

Figure 4. Comparison between experimental and predicted results in the degradation of the contaminants: (a) anthracene, (b) phenanthrene.

Despite the discrepancies, the proposed model is in good agreement with the data obtained under different conditions. A fixed set of parameters was used to validate the model based on the experimental data. Table 3 lists this set of fixed parameters and the adjusted parameters.

Table 3 Fixed and fitted parameters used in the modeling.

\begin{tabular}{ccc}
\hline Parameter & Value & Unity \\
\hline$k_{P}$ & $0.42^{(a)}$ & $\mathrm{I} \mathrm{mol}^{-1} \mathrm{~s}^{-1}$ \\
$k_{A}$ & $0.52^{(b)}$ & $\mathrm{I} \mathrm{mol}^{-1} \mathrm{~s}^{-1}$ \\
$K_{P A}$ and $K_{P P}$ & $1.62 \times 10^{-3}$ (b) & $\mathrm{Kg} \mathrm{l}^{-1}$ \\
$\alpha_{A}$ and $\alpha_{P}$ & $1.00^{(a)}$ & \\
$\beta_{A}$ and $\beta_{P}$ & $1.00^{(a)}$ & \\
\hline
\end{tabular}

${ }^{(\mathrm{a})}$ Fixed value from Forsey et al. (2010); ${ }^{(\mathrm{b})}$ Fitted value. 
In a thermodynamic study, Gutman and Stankovic (2007) found that phenanthrene is more stable than anthracene. Based on this study, a kinetic constant can be estimated for anthracene $\left(k_{A}\right)$, which is slightly higher than for phenanthrene $\left(\mathrm{k}_{\mathrm{p}}\right)$. At the beginning of the process, the calculated concentrations for anthracene and phenanthrene in solid matrix $\left([A]_{S}\right.$ and $\left.[P]_{S}\right)$ were 0.041 and $0.365 \mathrm{mg} \mathrm{I}^{-1}$, respectively. The solubilities of anthracene and phenanthrene in water are 0.07 and $1.29 \mathrm{mg} \mathrm{l}^{-1}$, respectively (ATSDR, 1995). These values were assumed to be the same for the $\mathrm{KMnO}_{4}$ solutions. It should be noted that the initial concentrations were lower than the solubility values. As the reaction proceeded the concentrations decreased, following the concept of partitioning. The contaminants did not reach the limit of solubility in the solution. Thus, the fitted value of the partition coefficients is coherent, since it justifies the slow reaction rate resulting from the low concentrations of contaminants. Anthracene and phenanthrene are isomers. Hence, it is expected that they have similar properties. Based on this, it was fitted the same value of partition coefficient for the two compounds. Despite the lack of rigor in this assumption, the value can be used as an estimative in order to obtain a mathematical description of the process.

\section{Conclusions}

It can be concluded that the degradation of anthracene and phenanthrene requires less $\mathrm{KMnO}_{4}$ than the stoichiometric value defined for total mineralization (reaction 1). This finding suggests a higher efficiency than expected when it is considered total degradation. This may be explained by the series of reactions involving the product $\mathrm{MnO}_{2}$, which showed that the contaminants are treated also for the $\mathrm{MnO}_{2}$ formed during the reaction between the $\mathrm{KMnO}_{4}$ and contaminants. The proposed model proved to be simple method for considering the complex oxidation mechanism, using a global reaction that accounts for the amount of $\mathrm{MnO}_{2}$ consumed. A full understanding of the process will enable us to determine whether $\mathrm{MnO}_{2}$ is in fact deposited on the particle surface, in order to prevent this from occurring. Thus, future modeling studies may enable the process to be optimized by increasing the degradation efficiency and/or by using less oxidant than the stoichiometry required dosage.

\section{Acknowledgments}

The authors acknowledge the funding agencies CAPES (Process \# 4959/10-8), CAPES/PROCAD (Process \# 213055), FAPESP (Process \# 08/57708-7) and INCT-EMA/CNPq (Process \# 610032/2009-7) for their financial support.

\section{References}

Akyol N.H. and Yolcubal I. (2013), Oxidation of nonaqueous phase trichloroethylene with permanganate in Epikarst, Water, Air \& Soil Pollution, 224:1573.

ATSDR - Agency for Toxic Substances and Disease Registry. Toxicological Profile for Polycyclic Aromatic Hydrocarbons (PAHs). 1995. Available at: http://www.atsdr.cdc.gov/toxprofiles/tp69.pdf

Brown G.S., Barton L.L. and Thomson B.M. (2003), Permanganate oxidation of sorbed polycyclic aromatic hydrocarbons, Waste Management, 23, 737-740.

Crimi M., Quickel M. and Ko S. (2009), Enhanced permanganate in situ chemical oxidation through MnO2 particle stabilization: Evaluation in 1-D transport systems, Journal of Contaminant Hydrology, 105, 69-79.

Doğan E., Accoe F., Boon N., Bastiaens L. and Dejonghe W. (2013), Impact of chemical oxidants on the heavy metals and the microbial population in sediments, Water, Air \& Soil Pollution, 224:1386.

EPA Method 3541. Automated Soxhlet Extraction. 1994. Available at: http://www.epa.gov/osw/hazard/testmethods/sw846/pdfs/3541.pdf

EPA Method 8270. Semivolatile Organic Compounds. 1999. Available at: http://www.epa.gov/region9/qa/pdfs/8270.pdf

Ferrarese E., Andreottola G. and Oprea I.A. (2008), Remediation of PAH-contaminated sediments by chemical oxidation, Journal of Hazardous Materials, 152, 128-139. 
Forsey S.P. In situ Chemical Oxidation of Creosote/Coal Tar Residuals: Experimental and Numerical Investigation. Thesis of the degree of Doctor of Philosophy in Earth Sciences, University of Waterloo, 2004.

Forsey S.P., Thomson N.R. and Barker J.F. (2010), Oxidation kinetics of polycyclic aromatic hydrocarbons by permanganate, Chemosphere, 79, 628-636.

Gutman I. and Stanković S. (2007), Why is phenanthrene more stable than anthracene?, Macedonian Journal of Chemistry and Chemical Engineering, 26, 111-114.

ITRC - Interstate Technology \& Regulatory Council. Technical and Regulatory Guidance for In Situ Chemical Oxidation of Contaminated Soil and Groundwater. 2ed. 2005. Available at: http://www.itrcweb.org/Documents/ISCO-2.pdf

Kim J. and Choi H. (2002), Modeling in situ ozonation for the remediation of nonvolatile PAH-contaminated unsaturated soils, Journal of Contaminant Hydrology, 55, 261-285.

Laha S. and Luthy R.G. (1990), Oxidation of aniline and other primary aromatic amines by manganese dioxide, Environmental Science and Technology, 24, 363-373.

Liang C. and Guo Y.-Y. (2012), Remediation of diesel-contaminated soils using persulfate under alkaline condition, Water, Air \& Soil Pollution, 223, 4605-4614.

Lo I.M.C., Tanboonchuy V., Yan D.Y.S., Grisdanurak N. and Liao C.H. (2012), A hybrid approach for PAHs and metals removal from field-contaminated sediment using activated persulfate oxidation coupled with chemicalenhanced washing, Water, Air \& Soil Pollution, 223, 4801-4811.

Mahmoudi N., Slater G.F. and Juhasz A.L. (2013), Assessing limitations for PAH biodegradation in long-term contaminated soils using bioaccessibility assays, Water, Air \& Soil Pollution, 224:1411.

Nadim F., Huang K.-C. and Dahmani A.M. (2006), Remediation of soil and ground water contaminated with PAH using heat and Fe(II)-EDTA catalyzed persulfate oxidation, Water, Air \& Soil Pollution Focus, 6, 227-232.

Perraudin E., Budzinski H. and Villenave E. (2007), Kinetic study of the reactions of ozone with polycyclic aromatic hydrocarbons adsorbed on atmospheric model particles, Journal of Atmospheric Chemistry, 56, 57-82.

Petri B.G., Watts R.J., Teel A.L., Huling S.G. and Brown R.A. (2011), Fundamentals of ISCO using hydrogen peroxide. In Situ Chemical Oxidation for Groundwater Remediation, SERDP/ESTCP Environmental Remediation Technology, 3, 33-88.

PSOD-1 - Permanganate Soil Oxidant Demand - Screening Phase- ASTM Method. Standard Test Method for Determining the Permanganate Soil Oxidant Demand. 2006. In Review. Available at: http://www.epa.gov/ada/topics/oxidation_issue.html

Stone A.T. (1987), Reductive dissolution of manganese (III/IV) oxides by substituted phenols, Environmental Science and Technology, 21, 979-988.

The New Dutch list. (2001), Available at: http://www.contaminatedland.co.uk/std-guid/dutch-I.htm\#10

Ukrainczyk L. and McBride M.B. (1992), Oxidation of phenol in acidic aqueous suspensions of manganese oxide. Clay Clay Miner., 40(2), 157-166.

USEPA, Engineering Issue Paper: In Situ Chemical Oxidation. (2006). EPA 600-R-06-072. Available at: http://www.clu-in.org/download/contaminantfocus/pcb/ISCO-600R06072.pdf

Yukselen-Aksoy Y., Khodadoust A.P. and Reddy K.R. (2010), Destruction of PCB 44 in spiked subsurface soils using activated persulfate oxidation, Water, Air \& Soil Pollution, 209, 419-427. 